\title{
Unusual case of recurrent thigh lump in a girl: a case report
}

\author{
Lasitha Samarakoon*, Tharanga Fernanado, Eshwari Liyanage, Himaru Wirithamulla and Kaluarachige Sunil Perera
}

\begin{abstract}
Introduction: Lipofibromatosis is a rare fibro-fatty tumour with a predilection to involve distal extremities. It has only recently been described as a distinctive clinicopathologic entity, and subsequently only a few cases have been published in the literature. To address the clinicopathologic significance of this rare entity, we here describe a case of lipofibromatosis occurring on the left thigh of a Sri Lankan girl who developed a recurrence following excision.

Case presentation: A 15-year-old previously healthy girl of Sri Lankan ethnicity presented with a painless progressively enlarging mass in her left thigh. Magnetic resonance imaging of her thigh lump, revealed a septated mass arising from subcutaneous tissue of anterolateral and medial aspects of her thigh. Histological assessment revealed evidence of lipofibromatosis, and the lesion was excised followed by split-skin grafting. She presented again with a local recurrence at the same site.
\end{abstract}

Conclusions: Adequate surgical excision leads to complete cure of this benign lesion, but recurrences are common following incomplete excision. Therefore awareness among clinicians of this rare entity is vital in offering the best possible care to the patients.

Keyword: Lipofibromatosis recurrence

\section{Introduction}

Lipofibromatosis is a recently described soft tissue tumour of obscure aetiology [1]. We present a case of a Sri Lankan girl presenting with a slow growing, painless mass in her left thigh, with histological evidence of lipofibromatosis.

\section{Case presentation}

A 15-year-old girl of Sri Lankan ethnicity presented with a painless progressively enlarging thigh lump for a period of 2 years. She was otherwise healthy. On examination a non-tender mass of soft consistency was noted arising from the anterior compartment of her thigh. There were no neurological and vascular compromises, and the lump was free of any deep attachments. Both hip and knee joints were clinically normal. Initial haematological investigations were within normal range.

Following initial investigation, she underwent a magnetic resonance imaging (MRI) scan of her left thigh. A $6 \mathrm{~cm}$ thick septate mass arising from subcutaneous tissue of anterolateral and medial aspects of her thigh was

\footnotetext{
* Correspondence: lasithamfc@gmail.com

General Surgical Unit, National Hospital of Sri Lanka, Colombo, Sri Lanka
}

noted. Contrast enhancement following intravenous gadolinium was not noted. Underlying muscle and bone were normal (Figures 1 and 2).

She underwent incisional biopsy under local anaesthesia subsequently. Histological diagnosis of lipofibromatosis of her left thigh was reached. Features of malignancy were not noted. The lesion was later excised and split-skin grafting was done. She was followed up as an out-patient and she developed a local recurrence after 10 months at the same site (Figure 3).

\section{Discussion}

Lipofibromatosis is a rare benign neoplasm usually occurring in childhood. Although it was previously designated as infantile fibromatosis of non-desmoid type [2], Fetsch et al. proposed that it should be classified as a separate entity as lipofibromatosis because it has distinct clinical and histological features [1].

Lipofibromatosis commonly presents as a painless slow growing mass affecting distal extremities, such as hands or feet, and, as was the case in our patient, in proximal limbs, trunk or even head and neck regions [3-5]. Aetiology of the tumour remains elusive to date [1]. 


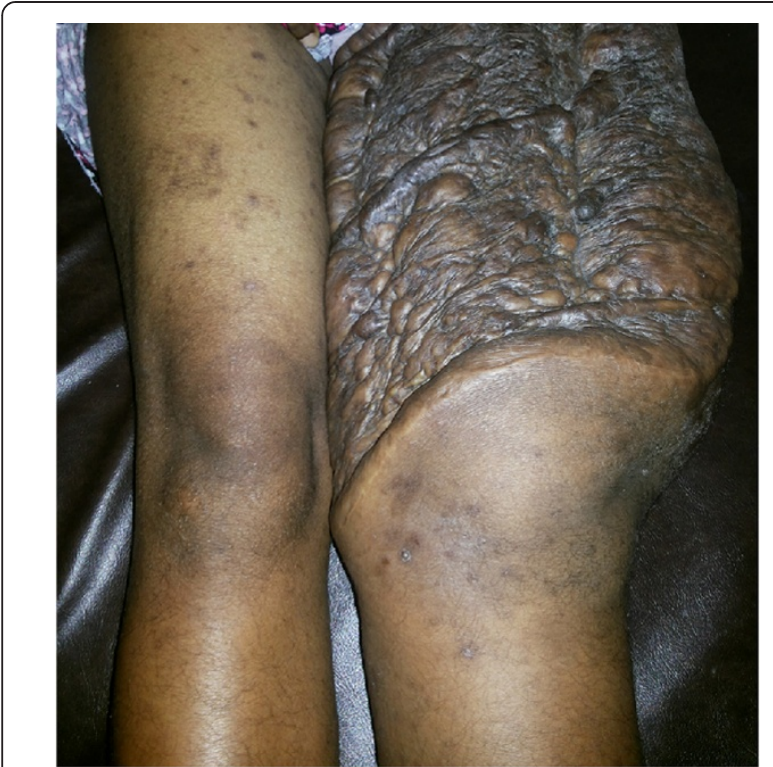

Figure 1 The patient presented with a painless progressively enlarging recurrent lump following excision on her left thigh, free of any deep attachments or neurovascular compromise.

On histological examination the tumour is mainly composed of mature adipose tissue [5]. Abundant fat tissue is separated by septa containing spindle fibroblast-like cells. They may have a primitive fibroblastic appearance; thus the lesion may mimic fibrous hamartoma of infancy.

Usually the mitotic rate is low and there is minimal cellular atypia [1]. Unlike fibromatosis, lipofibromatosis generally does not demonstrate solid, sheet-like fibrous growth.

Diagnosis can be made with distinctive histopathologic features, although immunohistochemical studies are an invaluable aid in doubtful cases [1,2]. Commonly,

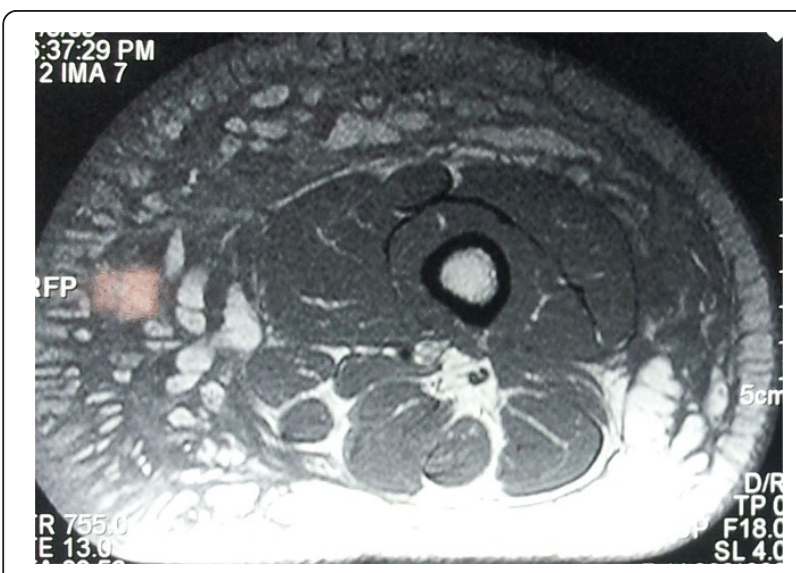

Figure 2 Magnetic resonance imaging scan of the thigh showing thick septate mass arising from subcutaneous tissue of anterolateral and medial aspects of the thigh without any contrast enhancement-transverse section.

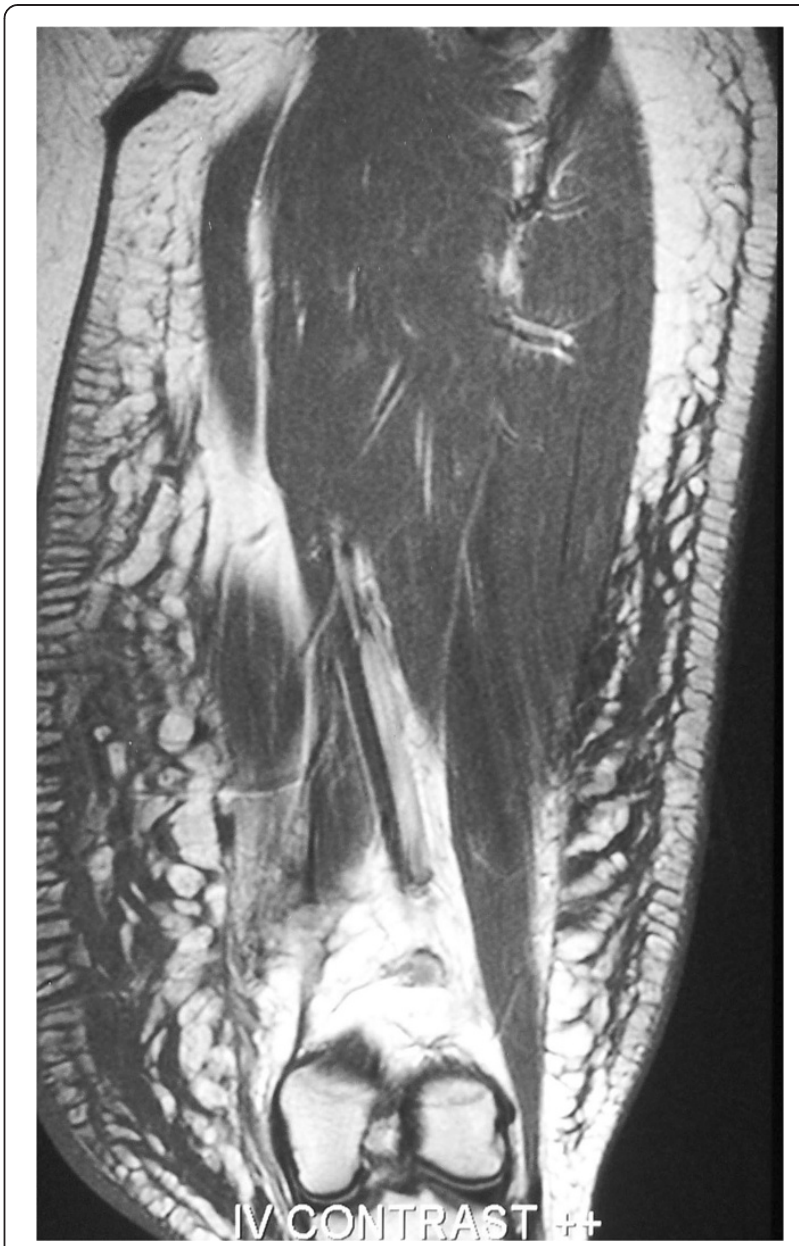

Figure 3 Magnetic resonance imaging of the thigh mass showing a sagittal section.

lipofibromatosis exhibits staining of the spindle cells with CD99, smooth muscle actin, BCL-2 and less commonly positivity for S-100 protein and epithelial membrane antigen. They stain typically negative to desmin $[1,2,6]$. Nuclear staining for beta-catenin by immunohistochemistry is commonly used to aid the diagnosis of fibromatoses, more so when the differential diagnosis includes other spindle cell tumours. In one study by Carlson and Fletcher, it was concluded that nuclear staining for betacatenin is supportive, but not definitive, of the diagnosis of desmoid fibromatosis as beta-catenin negativity does not preclude the diagnosis of fibromatosis [7].

Imaging is an invaluable adjunct to diagnosing these rare tumours. On MRI, the detection of fat within the tumour is a valuable distinguishing feature between lipofibromatosis and the other soft tissue fibrous tumours [5]. Radiological differential diagnosis includes lipofibromatosis hamartoma and Proteus syndrome.

Lipofibromatous hamartoma (macrodystrophia lipomatosa) of the nerves is a slow growing mass of fibro-fatty 
tissue surrounding and infiltrating major nerves. It is associated with macrodactyly and bone overgrowth [8].

The clinical criteria for Proteus syndrome include the presence of a connective tissue nevus, ovarian cystadenomas or parotid adenomas as well as vascular malformations [9].

Although it commonly presents as a painless slow growing mass, compression or entrapment of vessels, nerves and muscle has been reported previously with lipofibromatosis [2].

Lipofibromatosis is notorious for local recurrence, as was the case with our patient. A high recurrence rate was noted following incomplete resection [1]. Congenital onset, male gender and high mitotic count appear to be other risk factors for recurrence.

\section{Conclusions}

In conclusion, we propose that this rare and elusive clinical entity should be considered by clinicians and pathologists when encountering a soft tissue tumour in children and young adults. Although the number of documented cases is increasing, we believe that there is still insufficient clinical experience and lack of awareness about its existence. Since adequate surgical excision leads to complete cure of this benign lesion, awareness among clinicians is vital in offering the best possible care to the patients.

\section{Consent}

Written informed consent was obtained from the patient's legal guardian(s) for publication of this case report and any accompanying images. A copy of the written consent is available for review by the Editor-in-Chief of this journal.

\section{Abbreviation}

MRI: Magnetic resonance imaging.

\section{Competing interests}

The authors declare that they have no competing interests.

\section{Authors' contributions}

LS (registrar in surgery), TF and EL (intern medical officers) gathered data. LS prepared the manuscript. HW (senior registrar in surgery) and KSP (senior consultant in general surgery) made critical revisions to the original manuscript. LS, HW and KSP were responsible for overall surgical care of the patient. All authors read and approved the final manuscript.

\section{Acknowledgements}

We would like to acknowledge the contributions of Dr Manishka Amarasuriya, and Dr Dhulashiha Sivalingam (intern medical officers) in data gathering and overall medical care of the patient.

Received: 23 November 2013 Accepted: 19 May 2014

Published: 6 July 2014

\section{References}

1. Fetsch JF, Miettinen M, Laskin WB, Michal M, Enzinger FM: A clinicopathologic study of 45 pediatric soft tissue tumors with an admixture of adipose tissue and fibroblastic elements, and a proposal for classification as lipofibromatosis. Am J Surg Pathol 2000, 24(11):1491-1500.
2. Herrmann BW, Dehner LP, Forsen JW Jr: Lipofibromatosis presenting as a pediatric neck mass. Int J Pediatr Otorhinolaryngol 2004, 68(12):1545-1549.

3. Sasaki D, Hatori M, Hosaka M, Watanabe M, Kokubun S: Lipofibromatosis arising in a pediatric forearm - a case report. Ups J Med Sci 2005, 110(3):259-266.

4. Ayadi L, Charfi S, Ben Hamed Y, Bahri I, Gouiaa N, Khabir A, Makni S, Sellami-Boudawara T: Pigmented lipofibromatosis in unusual location: case report and review of the literature. Virchows Archiv Int J Pathol 2008, 452(4):465-467.

5. Teo HE, Peh WC, Chan MY, Walford N: Infantile lipofibromatosis of the upper limb. Skeletal Radiol 2005, 34(12):799-802.

6. Kabasawa Y, Katsube K, Harada H, Nagumo K, Terasaki H, Perbal B, Okada N, Omura $\mathrm{K}$ : A male infant case of lipofibromatosis in the submental region exhibited the expression of the connective tissue growth factor. Oral Surg Oral Med Oral Pathol Oral Radiol Endod 2007, 103(5):677-682.

7. Carlson JW, Fletcher CD: Immunohistochemistry for beta-catenin in the differential diagnosis of spindle cell lesions: analysis of a series and review of the literature. Histopathology 2007, 51(4):509-514.

8. Kameh DS, Perez-Berenguer JL, Pearl GS: Lipofibromatous hamartoma and related peripheral nerve lesions. South Med J 2000, 93(8):800-802.

9. Barclay L, Vogin G, Vega C: Cutaneous manifestations of Proteus syndrome reflect general severity. Arch Dermatol 2004, 140:1001-1002.

doi:10.1186/1752-1947-8-245

Cite this article as: Samarakoon et al: Unusual case of recurrent thigh lump in a girl: a case report. Journal of Medical Case Reports 2014 8:245.

\section{Submit your next manuscript to BioMed Central and take full advantage of:}

- Convenient online submission

- Thorough peer review

- No space constraints or color figure charges

- Immediate publication on acceptance

- Inclusion in PubMed, CAS, Scopus and Google Scholar

- Research which is freely available for redistribution 